\title{
KARAKTERISTIK KEPRIBADIAN ANTISOSIAL
}

\author{
Annisa Dwianggreni Kusuma*, Shania Ocha Sativa \\ Fakultas Kedokteran, Universitas Lampung, Jl. Prof. Dr. Ir. Soemantri Brojonegoro No.1, Gedong Meneng, Kec. \\ Raja Basa, Kota Bandar Lampung, Lampung, Indonesia 35145 \\ *annisakusuma36@gmail.com
}

\begin{abstract}
ABSTRAK
Secara epidemiologi gangguan kepribadian antisosial ditemukan sebanyak 2-4 \% pada laki-laki dan 0.5-1\% pada wanita. Prevalensi usia puncak ditemukannya kepribadian ini pada 24-44 tahun. Penegakkan diagnosis kepribadian ini dapat menggunakan PPDGJ III dan DSM-V. Metode yang digunakan dalam penelitian ini adalah studi literature review. Sumber pustaka yang digunakan dalam menyusun literatur ini terdiri dari buku pedoman, jurnal nasional, jurnal internasional, maupun website. Penelusuran sumber pustaka dilakukan melalui akses data NCBI dan Google Scholar terkait karakteristik kepribadian antisosial. Sumber pustaka yang digunakan terdiri dari 15 pustaka yang ditulis mulai dari tahun 1999 hingga 2019. Hasil penelitian menunjukkan gangguan kepribadian antisosial sering terjadi pada laki-laki di lingkungan penjara dan adanya abnormalitas pada grey matter lobus parietal otak dan white matter lobus oksipital. Simpulan gangguan kepribadian antisosial yaitu terlihat berkarisma, memiliki riwayat hidup dalam hal kriminal, tidak ada waham, pikiran tidak rasional, mudah menjebak orang terlihat dalam aktivitasnya dan khasnya yaitu tidak adanya penyesalan terhadap perbuatannya dikarenakan kurangnya kontrol empati dan perasaan terhadap orang lain.
\end{abstract}

Kata kunci: kepribadian antisosial, penegakkan diagnosis, prevalensi

\section{CHARACTERISTIC OF ANTISOSIAL PERSONALITY}

\begin{abstract}
Epidemiologically antisocial personality disorder is found as much as $2-4 \%$ in men and $0.5-1 \%$ in women. The peak age prevalence for this personality is found in 24-44 years. The management of this personality diagnosis can use PPDGJ III and DSM-V. The method used in this research is the literature review study. The method used is a literature review that was taken from a guidebook, national journals, international journals, and website. The literature consists of 15 library sources which are traced through NCBI aand Google Scholar data access. Literature Sources used were written in 1999 to 2019. The results showed antisocial personality disorder often occurs in men in prison environments and abnormalities in gray matter parietal lobes of the brain and white matter in the occipital lobe. Conclusions of antisocial personality disorder that is seen to be charismatic, have a history of life in criminal matters, no misunderstanding, irrational thoughts, easy to trap people seen in their activities and typically that there is no remorse for their actions due to lack of empathy control and feelings towards others.
\end{abstract}

Keywords: antisocial personality, diagnosis, prevalence

\section{PENDAHULUAN}

Kepribadian adalah kesatuan sistem antara sistem fisik dan psikologis seorang individu untuk menyesuaikan diri pada lingkungan. Kepribadian digambarkan melalui karakteristik unik seorang individu (Riadi, n.d.). Kepribadian juga merupakan keseluruhan perilaku dan emosi yang menjadi karakteristik unik seseorang yang stabil dan dapat diperdiksi (Mangindaan, 2017). Apabila kepribadian seseorang rigid dan tidak dapat beradaptasi yang menimbulkan masalah pada kehidupan sehari-hari yang bermakna maka itu adalah gangguan kepribadian (Kaplan HI, 2007).

Gangguan kepribadian berkisar 10-23 \% gangguan psikiatri (Kaplan HI, 2007; RJ, 2007). Gangguan Kepribadian memiliki beberapa macam separti gangguan kepribadian skizotipal, gangguan kepribadian paranoid, gangguan kepribadian antisosial, gangguan kepribadian dependen dan masih banyak lagi (Mangindaan, 2017).

Gangguan kepribadian merupakan bagian yang sering mengalami kesalahan diagnosis 
dikarenakan kurangnya penelitian pada bidang ini. Banyak orang yang memahami bahwa kepribadian antisosial merupakan gangguan kepribadian. Gangguan kepribadian dibutuhkan penatalaksanaan yang memiliki tantangan tersendiri (Casey, 1999).

Tahun 2020 terjadi kasus pemerkosaan di Inggris yang dilakukan oleh RHS, di kutip dari kompas.com menurut dr. Dharmawan RHS bisa saja disebut sebagai psikopat, tidak bisa merasakan perasaan (SA, n.d.). Pada kasus tersebut merupakan contoh ganggguan kepribadian antisosial atau psikopat. Gangguan Kepribadian antisosial digambarkan dengan pola perilaku pengabaian dan pelanggaran hak seseorang, pervasif, sejak usia dewasa muda dan nyata dalam berbagai konteks (Mangindaan, 2017).

Berbagai penguraian diatas, dirasa perlu untuk memahami karakteristik kepribadian antisosial sehingga dapat menghindari hal-hal yang tidak diinginkan. Literature review ini memiliki tujuan untuk memberikan informasi mengenai karakteristik kepribadian antisosial. Jenis penelitian ini adalah tinjauan pustaka dimana hasil dan pembahasannya didasarkan pada sumber ilmiah yang valid dan akurat.

\section{METODE}

Metode yang digunakan dalam penelitian ini adalah studi literature review. Sumber pustaka yang digunakan dalam menyusun literatur ini terdiri dari buku pedoman, jurnal nasional, jurnal internasional, maupun website. Penelusuran sumber pustaka dilakukan melalui akses data NCBI dan Google Scholar terkait karakteristik kepribadian antisosial. Sumber pustaka yang digunakan terdiri dari 15 pustaka yang ditulis mulai dari tahun 1999 hingga 2019.

\section{HASIL}

Secara epidemiologi gangguan kepribadian antisosial ditemukan sebanyak 2-4 \% pada laki-laki dan $0.5-1 \%$ pada wanita. Prevalensi usia puncak ditemukannya kepribadian ini pada usia 24-44 tahun dan menurun pada usia 45-64 tahun. Berdasarkan metode penilaian dan karakteristik sampel estimasi rasio penderita ganggguan kepribadian antisosial adalah 2:1 dan 6:1 pada laki-laki dan perempuan (Black, 2015).
Prevalensi gangguan kepribadian antisosial pada populasi umum didominasi oleh laki-laki. Prevalensi gangguan kepribadian antisosial di amerika utara pada laki-laki dan perempuan yaitu $4,6 \%$ dan $0,8 \%$. Prevalensi gangguan kepribadian di eropa pada laki-laki dan perempuan yaitu $1,3 \%$ dan $0 \%$ (National Collaborating Centre For Mental Health (UK), 2010).

Gangguan kepribadian antisosial banyak ditemukan pada lingkungan penjara. Prevalensi dari survei yang dilakukan didunia diapatkan prevalensi gangguan kepribadian antisosial pada laki laki $47 \%$ dan perempuan 21\% (Fazel \& Danesh, 2002). Menurut survei mental health and wellbeing di inggris didapatkan bahwa 2,8\%-4\% pada usia 18-64 tahun didiagnosis menderita gangguan kepribadian antisosial. Hasil perhitungan yang didapatkan bahwa laki-laki signifikan lebih tinggi mengalami gangguan kepribadian antisosial daripada perempuan yaitu 4,9\% dan 1,8\% (Pd et al., 2019).

Penelitian ini menggunakan fungtional magnetic resonance imaging (fMRI) untuk mempelajari perubahan konektivitas fungsi pada otak penderita gangguan kepribadian antisosial. Penilaian ini memiliki akurasi $86,57 \%$, sensitivitas 77,14 dan spesifisitas $96,88 \%$ dalam mendiagnosis penderita gangguan kepribadian antisosial dan individu normal. penelitian ini menunjukkan adanya abnormalitas pada bagian lobus otak penderita gangguan kepribadian antisosial dengan ditemukannya peningkatan grey matter pada lobus parietal dan white matter pada precuneus lobus oksipitalis (Tang et al., 2013).

\section{PEMBAHASAN}

Gangguan kepribadian antisosial sering terjadi pada lingkungan sosial yang kurang baik, awitan sebelum umur 15 tahun, tampak tenang, tampak dapat dipercaya, serta dicurigai adanya trauma fisik masa kecil dan trauma psikologis pada masa lampau (Fisher KA, 2019; Mangindaan, 2017). Pada kromosom 2 daerah 2p12 dengan variasi AVPR1A merupakan variasi dari gen reseptor oksitosin yang berkonstribusi dalam perilaku kepribadian antisosial didukung oleh pengaruh pertemanan yang sesat (Fisher KA, 2019).

Gangguan kepribadian antisosial tampak seperti berkarisma, memiliki riwayat hidup 
dalam hal kriminal, tidak ada waham, pikiran tidak rasional, mudah menjebak orang terlihat dalam aktivitasnya(Mangindaan, 2017)'(Kaplan HI, 2007). Tanda khasnya yaitu tidak adanya penyesalan terhadap perbuatannya dikarenakan kurangnya kontrol empati dan perasaan terhadap orang lain (Mangindaan, 2017; Santoso et al., 2017).

Pedoman diagnostik menurut PPDG III adalah (minimal 3 kriteria) yaitu bersikap tidak perduli perasaan orang lain. Secara menetap memiliki sikap tidak bertanggung jawab terhadap norma, peraturan, kewajiban sosial. Toleransi terhadap frustasi rendah dan ambang yang rendah untuk bertindak agresif atau kekerasan. Tidak mampu mempertahankan hubungan interpersonal walaupun tidak ada kesulitan. Tidak mampu menerima kesalahan atau belajar dari pengalaman atau hukuman. Sangat cenderung menyalahkan orang lain, atau memberikan rasionalisasi yang masuk akal untuk perilaku yang membuat pengidap konflik dengan masyarakat (Maslim, 2013).

Menurut Pedoman diagnostik DSM-V yaitu gangguan signifikan pada fungsi kepribadian meliputi penurunan fungsi diri

seperti identitas ego-Sentrism, arahan sendiri penentuan sasaran berdasarkan kepuasan pribadi, penurunan fungsi interpersonal seperti empati, ketidakmampuan untuk menjalin hubungan dengan orang lain karena adanya kecenderungan eksploitasi pada orang lain termasuk tipu daya (American Psychiatric Association, 2012).

Selain itu menurut DSM-V pedoman diagnosis laninnya berupa ciri-ciri kepribadian patologis seperti manipulatif, bohong, tak bereperasaan, dan permusuhan, tidak bertanggung jawab, impulsive, dan pengambialan resiko yang cenderung merusak diri. Gangguan fungsi kepribadian dan ekspresi individu yang relative stabil dan konsisten sepanjang waktu dan situasi. Gangguan fungsi kepribadian dan ekspresi individu yang tidak memahami perkembangan normative lingkungan sosial. Gangguan kepribadian dan ekspresi individu tidak semata-mata karena langsung efek fisiologis suatu zat atau kondisi medis umum. Individu setidaknya berusia 18 tahun(American Psychiatric Association, 2012).

Individu dengan gangguan kepribadian antisosial ini membutuhkan perawatan di rumah sakit agar membiasakan diri dalam bersosialisasi dengan teman sebaya agar menghindarkan mereka dari aturan yang mengekang seperti penjara. Anti depresan dan anti cemas dapat diberikan pada individu ini (Mangindaan, 2017; National Collaborating Centre For Mental Health (UK), 2010).

Penderita gangguan kepribadian antisosial memiliki prognosis yang baik dalam perkembangan kepribadiannya. Biasanya kegiatan kriminal yang mereka lakukan akan terungkap setelah 3 tahun. Setelah melakukan terapi mereka akan mengalami peningkatan hubungan intrapersonal. Namun, penderita gangguan kepribadian antisosial ini mengalami peningkatan angka kematian dini. Umur penderita biasanya $<40$ tahun. Angaka kematian ini meningkat akibat adanya bunuh diri, penyalahgunaan obat-obatan dan penyerangan (National Collaborating Centre For Mental Health (UK), 2010).

\section{SIMPULAN}

Gangguan kepribadian antisosial terlihat berkarisma, memiliki riwayat hidup dalam hal kriminal, tidak ada waham, pikiran tidak rasional, mudah menjebak orang terlihat dalam aktivitasnya dan khasnya yaitu tidak adanya penyesalan terhadap perbuatannya dikarenakan kurangnya kontrol empati dan perasaan terhadap orang lain. Dibutuhkan diagnosis dan penetalaksanaan yang tepat bagi penderita gangguan kepribadian antisosial.

\section{DAFTAR PUSTAKA}

American Psychiatric Association. (2012). DSM V: Antisosial Personality Disorder.

Black, D. W. (2015). The natural history of antisocial personality disorder. Canadian Journal of Psychiatry, 60(7), 309-314. https://doi.org/10.1177/07067437150600 0703

Casey, P. (1999). Antisocial Personality Disorder: an Epidemiological Perspective. Journal of the Royal Society of Medicine, 92(9), 489-489. https://doi.org/10.1177/01410768990920 0922

Fazel, S., \& Danesh, J. (2002). Serious mental disorder in 23000 prisoners: A systematic review of 62 surveys. Lancet, 359(9306), 545-550. https://doi.org/10.1016/S01406736(02)07740-1 
Fisher KA. (2019). Antisocial Personality Disorder. StatPearls Publishing.

Kaplan HI. (2007). Kaplan and Saddok's Synopsis of Phychiatry. Baltimore: William and Wilkins.

Mangindaan, L. (2017). Buku Ajar: Psikiatri (S. D. Elvira (ed.); 3rd ed.). Badan Penerbit Fakultas Kedokteran Universitas Indonesia.

Maslim, R. (2013). Buku saku: Diagnosis Gangguan Jiwa. PT. Nuh Jaya.

National Collaborating Centre For Mental Health (UK). (2010). Antisocial Personality Disorder: Treatment, Management And Prevention. British Psychological Society. https://www.ncbi.nlm.nih.gov/books/NB K55333/

Pd, A., Classification, I. S., \& Problems, R. H. (2019). Antisocial personality disorder: diagnosis and management Aetiology Box 1: Common factors observed in patients with an antisocial personality disorder.

Riadi, E. (n.d.). Pengaruh Kepribadian, Kecerdasan Emosional, Dan Perilaku Kewargaan Organisasi Terhadap Kinerja Kepala Sekolah Menengah Atas Dan Kejuruan Di Kota Tangerang. Jurnal Manajemen Pendidikan, 432-441.

RJ, W. (2007). Physchiatry for Medical Student. American Phychiatry Press.

SA, N. (n.d.). Kasus Reynhard Sinaga, Psikiater: Ada Penyimpangan Perilaku Seksual. Kompas.Com.

Santoso, M. B., Krisnani, H., \& Isna Deraputri, G. N. (2017). Gangguan Kepribadian Antisosial Pada Narapidana. Share: Social Work Journal, 7(2), 18. https://doi.org/10.24198/share.v7i2.1568 1

Tang, Y., Jiang, W., Liao, J., Wang, W., \& Luo, A. (2013). Identifying Individuals with Antisocial Personality Disorder Using Resting-State fMRI. PLOS ONE, $8(4)$.

https://doi.org/10.1371/journal.pone.0060 